\title{
PERANCANGAN PROTOTYPE APLIKASI TIKET WISATA DI KOTA PEMALANG MENGGUNAKAN UX LIFECYCLE
}

\author{
${ }^{1)}$ Khikma Mei Rida, ${ }^{2)}$ Gita Fadila Fitriana ${ }^{3)}$ Darmansah \\ ${ }^{1,2)}$ Program Studi Rekayasa Perangkat Lunak, Fakultas Informatika, Institut Teknologi Telkom Purwokerto \\ ${ }^{3}$ Program Studi Sistem Informasi, Fakultas Informatika, Institut Teknologi Telkom Purwokerto \\ ${ }^{1,2,3)}$ Jl. DI Panjaitan No.128, Karangreja, Purwokerto Kidul, Kec. Purwokerto Sel., Kabupaten Banyumas, Jawa \\ Tengah (53147) \\ E-mail : ${ }^{1)} 17104026 @$ ittelkom-pwt.ac.id, ${ }^{2)}$ gita@ittelkom-pwt.ac.id, ${ }^{3)}$ darmansah@ittelkom-pwt.ac.id
}

\begin{abstract}
ABSTRAK
Penelitian ini melakukan perancangan kebutuhan untuk memenuhi pelayanan konsumen, sehingga dibuatlah perancangan aplikasi tiket wisata di Kota Pemalang, dimana nantinya pada Aplikasi tiket wisata ini pengguna dapat mengetahui lokasi wisata yang dituju secara detail, memesan tiket secara online serta melakukan pembayaran tiket secara digital agar dapat memudahkan wisatawan dalam melakukan transaksi. Data terkumpul pada penelitian ini yaitu 30 responden dan dari 30 responden tersebut ada 21 responden masyarakat kota Pemalang mengalami kesulitan pada saat memesan tiket wisata di Kota Pemalang. Beberapa masyarakat mengatakan bahwa dalam pembelian tiket terkadang ada antrian yang panjang sehingga memerlukan waktu yang lama, Kesulitan dalam mengantri ketika membeli tiket wisata apalagi di saat weekend, dan Antrian terlalu panjang membuat malas. Statement ini merupakan pengambilan data secara langsung dibeberapa lokasi wisata dan menggunakan google form untuk mengetahui masalah yang dialami masyarakat di Kota Pemalang. Sehingga penulis membuat perancangan Prototype aplikasi Tiket Wisata untuk mempermudah wisatawan dalam memesan tiket. Proses perancangan prototype aplikasi dilakukan dengan menggunakan metode User Experience Lifecycle dan metode the wheel digunakan untuk metode perancangan. Metode the wheel digunakan untuk menilai usability. Pengujian usability pada aplikasi Tiket Wisata dilakukan untuk mengetahui pengalaman dan respon dari pengguna pada saat menggunakan aplikasi pemesanan tiket wisata di Kota Pemalang, apakah aplikasi tersebut sudah layak digunakan dan sudah sesuai dengan keinginan pengguna. Metode yang digunakan untuk menguji aplikasi yaitu metode System Usability Scale (SUS). Aplikasi Tiket Wisata di Kota Pemalang, maka pengukuran usability pada prototype aplikasi tiket wisata Pemalang memenuhi tingkat efisiensi dengan nilai relatif keseluruhan sebesar 77,1667, tingkat efektivitas presentase dari keseluruhan task seluruh reponden sebesar 96,1\%.
\end{abstract}

Kata Kunci: Metode the wheel, System Usability Scale, Aplikasi Tiket Wisata, User Experience Lifecycle

\section{ABSTRACT}

This business requires the help of information technology that can improve customer service quickly and accurately. This study designs the needs to meet consumer service, so a tourist ticket application design is made in Pemalang City, which in this tourist ticket application users can find out the destination tourist locations in detail, order tickets online and make digital ticket payments in order to make it easier tourists in making transactions. The data collected in this study were 30 respondents and of the 30 respondents there were 21 respondents from Pemalang city community who had difficulty when ordering tourist tickets in Pemalang City. Some people say that when buying tickets there are sometimes long queues that take a long time, Difficulty in queuing when buying tourist tickets, especially on weekends, and too long queues make you lazy. This statement is a direct data collection at several tourist sites and uses a google form to find out the problems experienced by the people in Pemalang City. So that the authors make the design of the Prototype of the Travel Ticket application to make it easier for tourists to order tickets. The application prototype design process is carried out using the User Experience Lifecycle method and the wheel method is used for the design method. The wheel method is used to assess usability. Usability testing on the Travel Ticket application was carried out to determine the experience and response of users when using the tourist ticket booking application in Pemalang City, whether the application was suitable for use and was in accordance with the wishes of the user. The method used to test the application is the System Usability Scale (SUS) method. Tourist Ticket Application in Pemalang City, the usability measurement on the prototype of the Pemalang tourist ticket application meets the efficiency level with an overall relative value of 77.1667 , the percentage effectiveness level of the entire task of all respondents is $96.1 \%$.

Keyword: The wheel method, System Usability Scale, Travel Ticket Application, User Experience Lifecycle 


\section{PENDAHULUAN}

Teknologi yang berkembang pada bidang bisnis mengalami kemajuan yang signifikan. Salah satu bidang bisnis yang mengalami percepatan dalam bidang teknologi informasi pada sektor pariwisata. Sektor pariwisata harus memiliki kualitas, pelayanan dan metode pemasaran yang terbaru [1].

Peningkatan kualitas dan kinerja harus disertai dengan kemajuan teknologi informasi. Sektor pariwisata, pemesanan tiket wisata menjadi salah satu bisnis yang membutuhkan bantuan teknologi informasi yang cepat dan tepat [2].

Pemesanan tiket wisata didukung dengan aplikasi berbasis mobile yang telah banyak digunakan pada era saat ini. Dimana hal tersebut banyak memunculkan aplikasi yang dirancang agar meningkatkan kualitas pelayanan dalam pemesanan tiket wisata. Aplikasi berbasis mobile saat ini dilengkapi dengan internet yang mudah diakses dimanapun [1].

Tersebarnya jaringan internet saat ini dapat memudahkan kegiatan manusia terutama dalam hal terkait proses pemesanan dan pembelian tiket wisata. Saat ini proses pembelian tiket wisata sudah bergeser dari semula dalam bentuk fisik menjadi transaksi secara online. Penggunaan internet dapat dilakukan dimana saja dan kapan saja secara cepat, efisien dan efektif [3]. Hal tersebut menjadi dasar untuk membuat prototype sistem aplikasi tiket wisata yang menyajikan informasi detail terkait wisata tersebut serta fasilitas pemesanan tiket.

Melalui aplikasi tiket wisata ini pengguna dapat mengetahui lokasi wisata yang dituju secara detail, memesan tiket secara online serta melakukan pembayaran tiket secara digital agar dapat memudahkan wisatawan dalam melakukan transaksi. Dalam merancang prototype tersebut penulis melakukan observasi melalui pengumpulan data menggunakan kuesioner online yang dibagikan kepada masyarakat terutama di Kota Pemalang sendiri. Data menyatakan dari 21 responden atau $47,6 \%$ masyarakat kota Pemalang mengalami kesulitan pada saat memesan tiket wisata di Kota Pemalang. Beberapa masyarakat mengatakan bahwa dalam pembelian tiket terkadang ada antrian yang panjang sehingga memerlukan waktu yang lama, Kesulitan dalam mengantri ketika membeli tiket wisata apalagi disaat weekend, dan Antrian terlalu panjang membuat malas. Sehingga penulis membuat perancangan Prototype aplikasi Tiket Wisata untuk mempermudah wisatawan dalam memesan tiket. Proses perancangan prototype aplikasi dilakukan dengan menggunakan metode User Experience Lifecycle.

\section{User Experience Lifecycle (UXL)} merupakan metode perancangan yang menggunakan pendekatan the wheel yang digagas oleh Hartson dan Pyla dengan memperhatikan aspek usability dan pengalaman pengguna. Metode ini memiliki empat tahap yaitu analisa, desain, prototipe, dan evaluasi [4]. Metode ini membuat dan memperbaiki desain yang bertujuan untuk menciptakan pengalaman pengguna yang berkualitas [5]. Pada penelitian ini menggunakan usability testing method sebagai evaluasi prototype.

Usability Testing merupakan suatu pengujian atau evaluasi perangkat lunak, usablity testing itu sendiri merupakan suatu metode untuk mengevaluasi perangkat lunak atau sistem dengan menguji perangkat tersebut dengan melibatkan pengguna secara langsung. Tingkat usability digunakan sebagai 
pengukuran usability pada produk atau layanan sebagai pencapaian kemudahan pengguna [6]. Menurut Jacob Nielson Usability testing atau pengujian ketergunaan memiliki lima komponen utama yaitu learnability efficiency, memorability, errors dan satisfaction [4]. Pengujian usability pada aplikasi Tiket Wisata dilakukan dengan menggunakan metode System Usability Scale (SUS). Pengukuran usability dari sudut pandang pengguna secara subyektif dapat dilakukan dengan kuesioner SUS [7].

\section{Penelitian Sejenis}

Aplikasi mobile penjualan tiket online atau Aplikasi mobile ticketing adalah suatu terobosan dari instansi transportasi maupun $e$ commerce untuk mempermudah dan mempermudah akses pengguna transportasi yang ingin melakukan transaksi tanpa harus datang ke tempat pelayanan tiket. Oleh karena itu perlu adanya pendekatan $U X$ untuk mengukur kepuasan pelanggan dalam menggunakan aplikasi mobile ticketing[8].

Evaluasi tingkat kebergunaan aplikasi administrasi penduduk menggunakan system usability scale adalah aplikasi administrasi penduduk desa sebagai usaha untuk mencapai tertib administrasi, terutama berkaitan dengan data penduduk. Penelitian ini mengusulkan evaluasi tingkat kebergunaan aplikasi dengan teknik System Usability Scale (SUS)[9].

\section{METODE}

Metode yang digunakan pada penelitian ini adalah User Experience Lifecycle (UXL), metode ini digunakan untuk melihat pengalaman pengguna pada saat menggunakan aplikasi tiket wisata di Kota Pemalang. Selanjutnya metode untuk pengujian data yang digunakan yaitu System Usability Scale (SUS).
Pada bab ini menjelaskan teori tentang UXL dan SUS, selanjutnya pada bab Hasil dan Pembahasan terdapat pengolahan data untuk aplikasi tiket wisata di Kota Pemalang.

\section{User Experiance Lifecycle (UXL) adalah} metode yang memperhatikan pengalaman pengguna serta melibatkan beberapa tahapan dalam sebuah siklus. Siklus ini terdiri dari empat aktivitas, yaitu analisis, desain, prototipe dan evaluasi. Metode ini (UXL) juga dinamakan dengan The Wheel

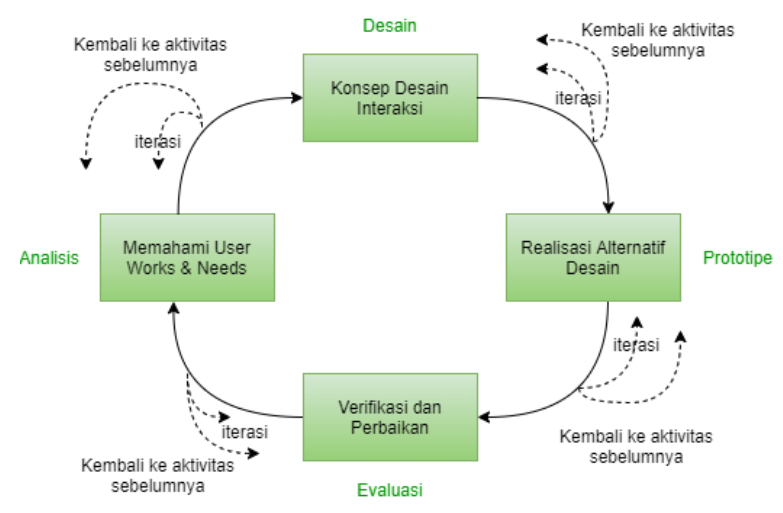

Gambar 1 User Experience Lifecycle

Konsep UXL suatu metode yang lebih berfokus kepada pengalaman pengguna. Pada fase implementasi, fase ini meliputi komponen desain interaksinya. Untuk prototipe merupakan pengembangan dari desain yang dirancang sebelumnya. Selanjutnya dilakukan evaluasi sebelum produk dirilis.

\section{A. Analisis}

Tahapan ini meliputi meliputi pengumpulan informasi mengenai kebiasaan, kebutuhan, keinginan, perasaan, dan permasalahan yang dirasakan pengguna ketika menggunakan aplikasi Tiket Wisata di Kota Pemalang. Terdapat empat proses dalam tahapan analisis yaitu contextual inquery, contextual analysis, user needs \& requirements, dan design informing models. Tahapan analisis menghasilkan System concept 
statement, flow model, work activity affinity diagram, dan social model[4].

\section{B. Design}

Tahap desain dilakukan untuk merancang interaksi dan konsep dari aplikasi Tiket Wisata di Kota Pemalang. Tahap ini terdiri dari tiga tahap, yaitu design thinking and ideation, conceptual design, dan design production. Tahap desain menghasilkan persona, storyboard dan wireframe [4].

\section{Prototipe}

Tahap prototipe bertujuan untuk membuat tampilan antarmuka pengguna dalam bentuk prototipe yang cepat dan mudah diubah. Prototipe yang dibuat merupakan gambaran bagaimana produk akhir dari aplikasi yang dibuat bekerja. Low fidelity prototype merupakan prototipe yang dikembangkan terlebih dahulu. Prototipe jenis ini dibuat berdasarkan data dari user persona, sketsa dan wireframe. Prototipe dilanjutkan pada medium-fidelity, yaitu prototipe yang memenuhi seluruh fungsi utama dan memiliki tampilan mirip dengan produk akhir[4]. Pembuatan prototipe dilakukan dengan menggunakan aplikasi Framer.

\section{Evaluasi}

Pengujian usability dapat dilakukan pada perangkat lunak yang kecil maupun besar dan multiplatform seperti berbasis dekstop, web, dan mobile. Fokus dari pengujian usability adalah kemudahan menggunakan perangkat lunak oleh pengguna[10]. Evaluasi usability bertujuan mendapatkan timbal balik dari pengguna mengenai pengalamannya. Selain itu, evaluasi usability juga bertujuan mengawasi penggunaan dan perkembangan produk atau sistem secara berkala[11]. Prototipe yang sudah selesai kemudian dievaluasi kepada responden. Prototipe diuji menggunakan metode System Usability Scale
(SUS). System Usability Scale (SUS) merupakan kuesioner yang dapat digunakan untuk mengukur usability sistem komputer menurut sudut pandang subyektif pengguna. SUS dikembangkan oleh John Brooke sejak 1986[12].

Skor SUS keseluruhan diperoleh dari rata-rata skor SUS individual. Berdasarkan penilaian di atas maka rumus perhitungan skor SUS[13]:

$S U S=2,5 \times\left[\sum_{n=1}^{5}\left(U_{2 n-1}-1\right)+\left(5-U_{2 n}\right]\right.$ (1)

Berdasarkan rumus (1) menghitung nilai SUS score percentile rank berdasarkan hasil perhitungan penilaian pengguna. Ketentuan penilaian SUS score percentile rank, rata-rata skor SUS yang baik adalah 68, apabila dibawah 68 dapat dikatakan pengguna tidak puas terhadap sistem [14].

Pengujian aplikasi dilakukan menggunakan usability testing dengan pengguna diberikan beberapa task/tugas yang harus diselesaikan. Task diberikan kepada 30 responden yang nantinya akan di analisis dari hasil pengujian. Berikut pengujian yang dilakukan :

\section{Efektivitas}

Efektivitas dapat dihitung dengan mengukur tingkat penyelesaian dari task. Tingkat penyelesaian dihitung dengan menetapkan nilai biner '1' jika peserta tes berhasil menyelesaikan tugas dan ' 0 ' jika tidak[15]. Efektivitas dengan demikian dapat direpresentasikan sebagai persentase dengan menggunakan persamaan sederhana ini :

\section{Effectiveness $=$}

$\frac{\text { Number of tasks completed successfully }}{\text { Total number of tasks undertaken }} \times 100 \%$ 
(2)

\section{Efisiensi}

Efisiensi digunakan untuk mengukur waktu participant dalam menyelesaikan task. Efisiensi kemudian dapat dihitung dengan salah satu dari 2 cara yaitu menggunakan rumus (2) efisiensi berdasarkan waktu (time based efficiency) dan rumus (3) efisiensi relatif keseluruhan (overall relatif efficiency)[15].

Time Based Efficiency $=$ $\frac{\sum_{j=}^{R} \sum_{i=1}^{N} \frac{n_{i j}}{t_{i j}}}{N R} \times 100 \%$

Overall relative efficiency menggunakan rasio waktu yang dibutuhkan oleh pengguna yang berhasil menyelesaikan tugas dalam kaitannya dengan total waktu yang diambil oleh semua pengguna. Persamaan tersebut dengan demikian dapat direpresentasikan sebagai berikut:

$$
\begin{aligned}
& \text { OverallRelativeEfficiency }= \\
& \qquad \frac{\sum_{j=\sum_{i=1}^{R} n_{i j} t_{i j}}^{N}}{\sum_{j=\sum_{i=1}^{N} t_{i j}}^{N}} \times 100 \%
\end{aligned}
$$

\section{HASIL}

\section{Contextual Inquery}

Hasil wawancara dengan salah satu pengurus di dinas pariwisata bernama Ibu Rusmiati, wawancara dilakukan di Pantai Widuri Pemalang. Ibu Rusmiati mengakui belum pernah menemukan aplikasi semacam pemesanan tiket wisata di kota Pemalang. Ibu Rusmiati mengakui membutuhkan layanan ini, karena berharap dapat mempermudah para wisatawan untuk berkunjung dan mendapatkan informasi yang detail sesuai dengan data yang terdapat pada masing-masing wisata.
Narasumber berharap dengan adanya aplikasi Tiket Wisata Pemalang dapat memberikan layanan yang diinginkan seperti detail wisata yang akurat, harga tiket yang sesuai dan maps untuk mempermudah wisatawan mencari lokasi wisata. Selain itu belum adanya aplikasi yang sejenis yang terdapat di Pemalang untuk mempermudah melakukan pembelian tiket wisata. Untuk memvalidasi data lebih lanjut peneliti melakukan penelitian lain menggunakan kuesioner online.

Kuesioner online berupa pertanyaan untuk mengetahui pengalaman dan kebutuhan pengguna untuk melakukan transaksi pembelian tiket. Kuesioner di berikan kepada 21 reponden atau 47,6\% masyarakat kota Pemalang mengalami kesulitan pada saat memesan tiket wisata di Kota Pemalang. Beberapa masyarakat mengatakan bahwa dalam pembelian tiket terkadang ada antrian yang panjang sehingga memerlukan waktu yang lama, Kesulitan dalam mengantri ketika membeli tiket wisata apalagi disaat weekend, dan Antrian terlalu panjang membuat malas.

\section{Contextual Analysis}

Alur dan hubungan antara pengguna dengan perangkat yang digunakan. Pengguna menggunakan aplikasi untuk melakukan transaksi pembelian tiket serta lokasi wisata yang akan dituju. Pada Gambar 2 di bawah ini merupakan flow model :

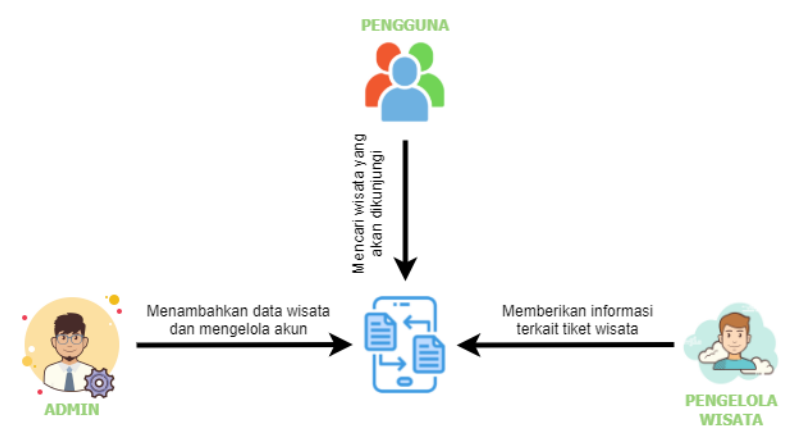




\section{Gambar 2 Flow Model}

Work Activity Affinity Diagram (WAAD) merupakan suatu metode atau alat brainstorming yang menggunakan diagram untuk mengelompokkan sejumlah besar ideide ke dalam relasi alamiah mereka[9]. Gambar 3 adalah Work Activity Affinity Diagram (WAAD) :

\begin{tabular}{|c|}
\hline Fungsionalitas \\
\hline $\begin{array}{c}\text { Dapat memesan tiket } \\
\text { wisata pada aplikasi }\end{array}$ \\
\hline $\begin{array}{c}\text { Dapat melihat harga } \\
\text { tiket wisata }\end{array}$ \\
\hline $\begin{array}{c}\text { Dapat melihat detail } \\
\text { wisata }\end{array}$ \\
\hline $\begin{array}{c}\text { Dapat melihat lokasi } \\
\text { wisata (maps) }\end{array}$ \\
\hline $\begin{array}{c}\text { Dapat melihat review } \\
\text { Dapat melakukcan fitur } \\
\text { search }\end{array}$ \\
\hline Terdapat profile \\
\hline Terdapat riwayat \\
pembelian tiket
\end{tabular}

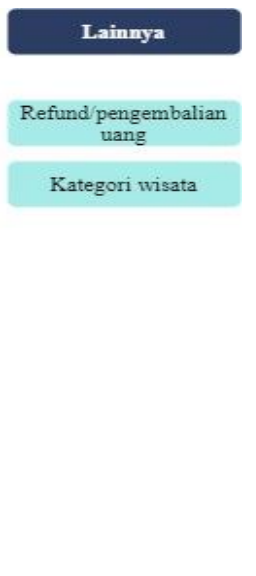

Gambar 3 Activity Affinity Diagram

Gambar 3 terdapat dua permasalahan yaitu bagian fungsionalitas dan lainnya. Fungsionalitas adalah fitur-fitur yang terdapat pada sistem aplikasi Tiket Wisata Pemalang, yaitu memesan tiket wisata, melihat harga tiket, melihat lokasi wisata, melihat review, melakukan fitur search, melihat profile dan riwayat pembelian tiket wisata. Sementara itu di bagian lainnya merupakan fitur yang tidak terdapat pada aplikasi Tiket Wisata Pemalang, yaitu Refund pengembalian uang dan kategori wisata.

\section{Extracting Design Requirement}

Hasil dari Work Activity Affinity Diagram dapat diterapkan ke dalam tabel Extracting Design Requirement. Pada gambar 4 di bawah ini berisi fitur-fitur yang dapat di implementasikan dan tidak atau belum dapat diimplementasikan saat ini.

\begin{tabular}{|c|l|c|c|}
\hline ID & \multicolumn{1}{|c|}{ Work Activity Note } & $\begin{array}{c}\text { System } \\
\text { Requirements }\end{array}$ & Feasibility \\
\hline A.1 & Memesan tiket wisata & Fitur Utama & $\mathrm{V}$ \\
\hline A.2 & Dapat melihat harga tiket wisata & Fitur Utama & $\mathrm{v}$ \\
\hline A.3 & Dapat melihat detail wisata & Fitur Utama & $\mathrm{v}$ \\
\hline A.4 & Dapat melihat lokasi (maps) & Fitur Utama & $\mathrm{V}$ \\
\hline A.5 & Dapat melakukan fitur search & Fitur Utama & $\mathrm{v}$ \\
\hline A.6 & Terdapat profile & Fitur Utama & $\mathrm{v}$ \\
\hline A.7 & Terdapat riwayat pemesanan & Fitur Utama & $\mathrm{v}$ \\
\hline B.1 & Refund pengembalian uang & Fitur Lainnya & $\mathrm{x}$ \\
\hline B.2 & Kategori wisata & Fitur Lainnya & $\mathrm{x}$ \\
\hline
\end{tabular}

Gambar 4 Extracting Design Requirement

\section{Design Informing Model}

Social Model menghasilkan desain yang melihat semua hambatan atau masalah yang diidentifikasi dalam model dan menyelesaikan masalah yang mereka miliki. Terlihat seperti Gambar 5 di bawah ini :

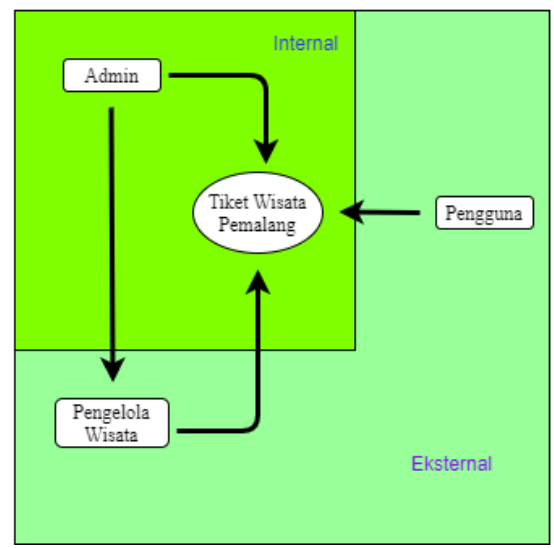

Gambar 5 Social Model

Komponen internal adalah interaksi yang terjadi di dalam sistem tersebut, diantaranya yaitu interaksi antara admin dengan aplikasi Tiket Wisata Pemalang dan admin dengan pengelola wisata. Sedangkan komponen eksternal adalah komponen yang berada di luar sistem, seperti interaksi pengguna dengan aplikasi Tiket Wisata Pemalang dan pengelola wisata dengan sistem aplikasi Tiket Wisata Pemalang.

\section{Design Thinking and Ideation}

Design Thinking dilakukan dengan pembuatan persona gambaran dari proses melakukan tanya jawab kepada pengguna 
melalui sistem aplikasi yang dirancang. Elemen-elemen pada persona didasarkan kepada kebutuhan pengguna. Berdasarkan hasil wawancara dan kuesioner pada tahap analisis. Adapun persona dapat dilihat pada Gambar 6 di bawah ini:

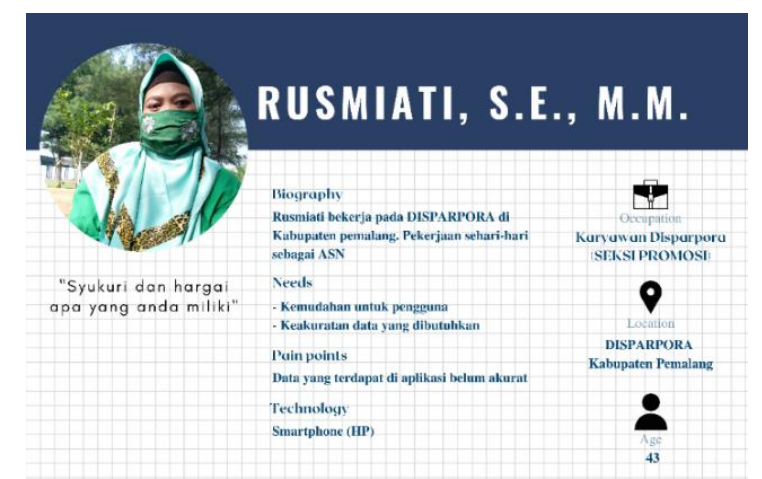

Gambar 6 User Persona

\section{Conceptual Design}

Conceptual Design merupakan frame yang terurut mendeskripsikan atau menggambarkan hubungan antara pengguna dengan sistem. Skenario sebelum menggunakan sistem ini yaitu pengguna merasa kesulitan ketika memesan tiket pada saat hari libur atau weekend karena terlalu banyak pengunjung wisata. Terlihat seperti Gambar 7 di bawah ini :

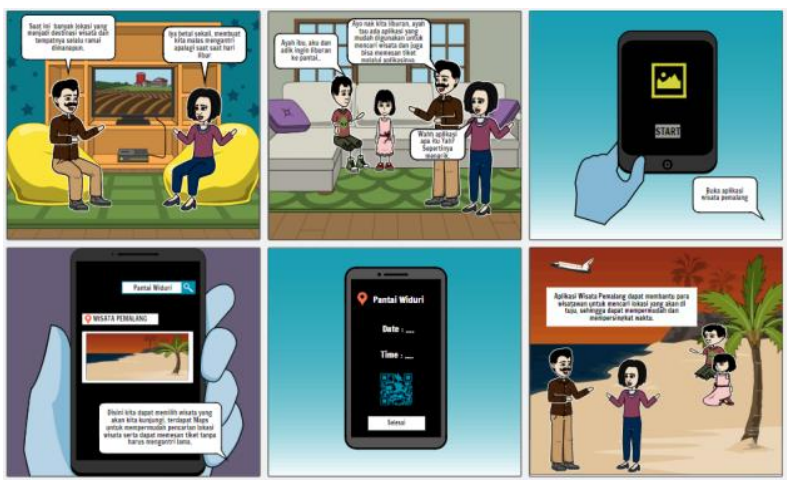

Gambar 7 Storyboard Aplikasi Tiket Wisata

Skenario gambar 7 Aplikasi Tiket Wisata Pemalang bermula ketika ada seorang pengguna yang sedang berbincang mengenai destinasi wisata yang selalu ramai pada saat hari libur / weekend, selanjutnya mereka akan mengunjungi salah satu wisata yang ada di Pemalang dan menemukan solusi untuk memesan tiket melalui sebuah aplikasi Tiket Wisata di Kota Pemalang. Aplikasi tersebut memiliki fitur seperti pilihan wisata, lokasi wisata dan dapat memesan tiket secara online. Apabila sudah booking tiket yang dipilih, akan menampilkan sebuah barcode yang nantinya akan ditunjukkan ke pengelola wisata/tempat pembelian tiket di tempat wisata.

\section{Design Production}

Proses Design Production dilakukan dengan membuat sebuah wireflame yang bertujuan untuk menyampaikan susunan, struktur, layout, navigasi dan organisir konten. Terlihat seperti Gambar 8 dibawah ini :

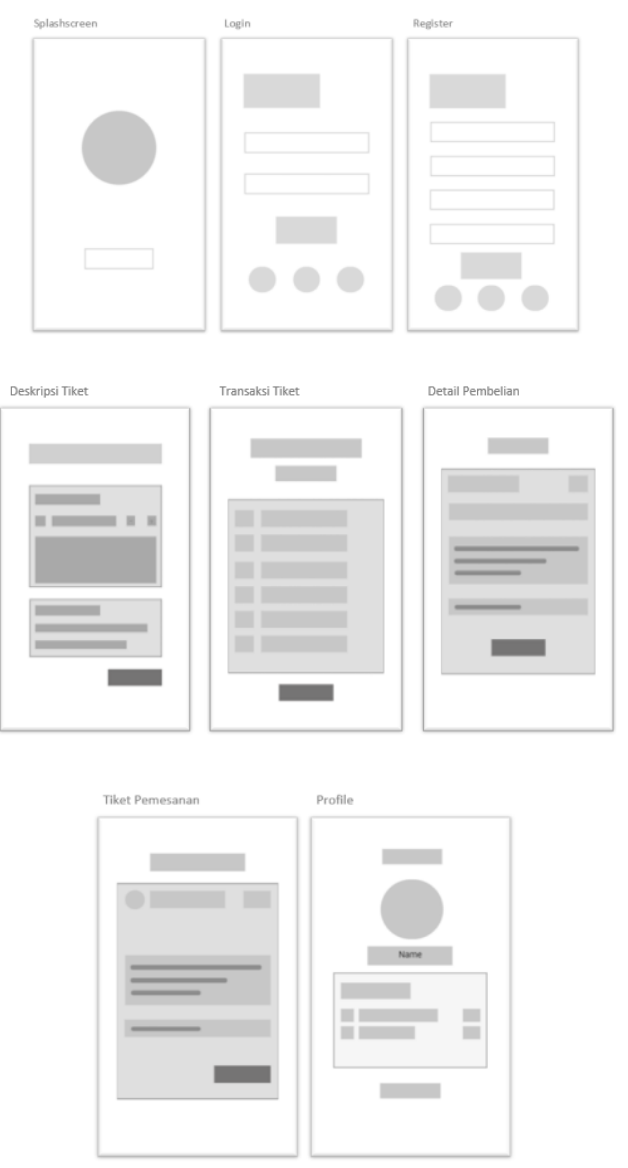

Gambar 8 Wireframe Aplikasi Tiket Wisata 
Proses pada gambar 8 merupakan penggambaran Wireframe yang dibuat dengan warna hitam putih dimana lebih menekankan isi dari sebuah konten, sebelum nantinya menjadi design yang berwarna atau biasa disebut dengan prototype. Pada wireframe gambar 8 terdapat splashscreen, login, register, deskripsi tiket, transaksi tiket, detail pembayaran, tiket pemesanan, dan profile. Selanjutnya design yang sudah jadi (prototype) terdapat pada Gambar selanjutnya/ Gambar 9.

\section{Prototype}

Prototype merupakan sebuah proses perancangan sebuah sistem, yang dimana tingkat prototype yang digunakan yaitu medium fidelity. Terdapat pada gambar 9 di bawah ini:
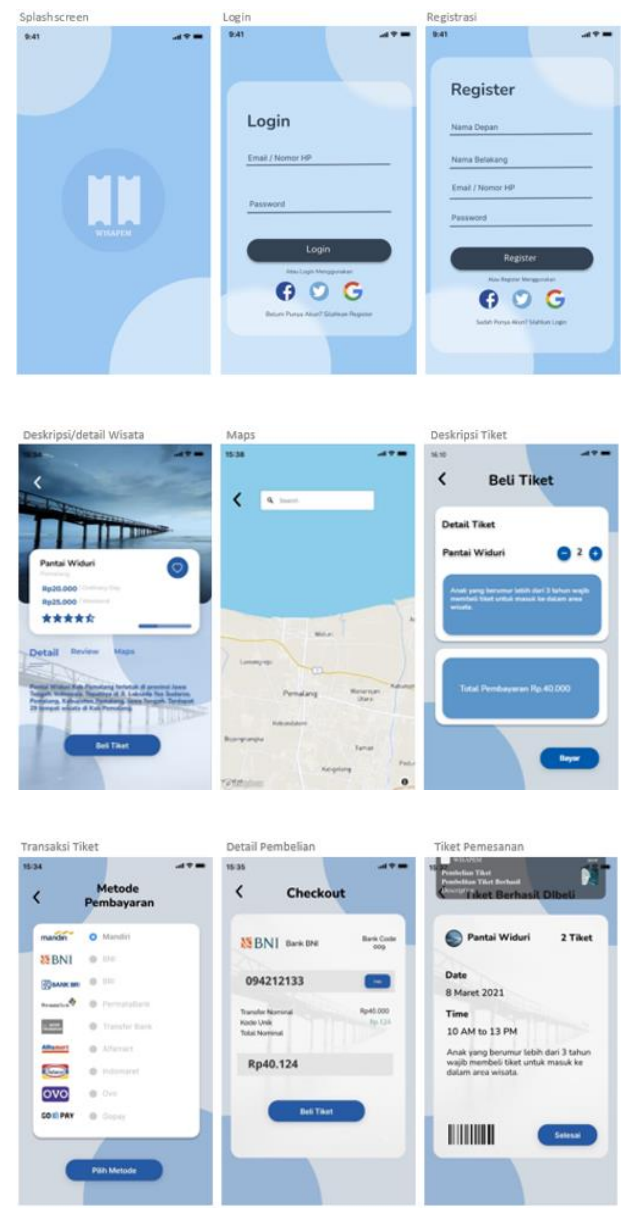

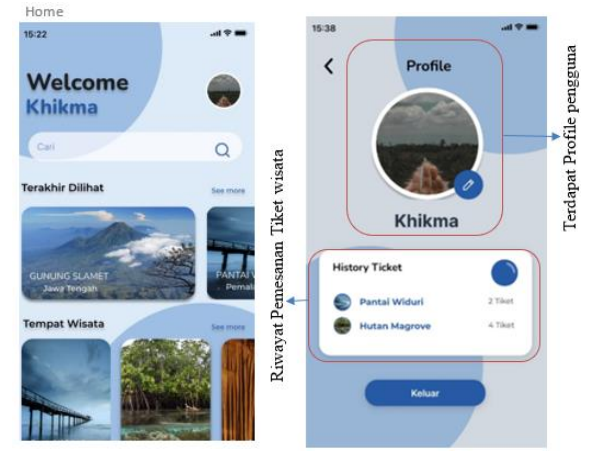

Gambar 9 Prototype Aplikasi Tiket Wisata

Gambar 9 yang merupakan hasil prototype dari aplikasi Tiket Wisata di Kota Pemalang. Penjelasan dari design ini ada Splashscreen : ini merupakan logo dari aplikasi tiket wisata di Kota Pemalang, Login : mencantumkan alamat email/nomor hp yang sudah terdaftar dan password, Registrasi : apabila belum memiliki akun penggguna harus mendaftar terlebih dahulu dengan mengisi nama depan, nama belakang, email/nomor hp, dan password, selanjutnya Deskripsi detail wisata : menampilkan deskripsi dari wisata yang akan dituju seperti harga tiket, review dan maps, Maps : menampilkan detail lokasi wisata, Deskripsi tiket : untuk menentukan jumlah tiket yang akan dibeli, Transaksi tiket : memilih metode pembayaran, Deskripsi pembelian : menampilkan total selutuh harga tiket dan terdapat kode disetiap pembayarannya, Tiket pembelian : tiket telah berhasil dibayar/dibeli dan akan muncul barcode untuk mempermudah pada saat datang ke lokasi wisata, Home : menampilkan berbagai macam destinasi wisata dan fitur search, Profile : akun yang dimiliki oleh pengguna.

\section{Hasil Evaluasi (SUS)}

Langkah awal pengujian usability (usability testing) ini adalah dengan memberikan beberapa task atau tugas yang 
sudah dipersiapkan sebelumnya kepada pengguna saat berinteraksi dengan aplikasi Wisata di Kota Pemalang yang diuji. Task atau tugas tersebut diberikan kepada 30 responden (participant). Dibawah ini merupakan Task dari aplikasi Tiket Wisata di Kota Pemalang :

Tabel 1 Task/Tugas Aplikasi Tiket Wisata

\begin{tabular}{cl}
\hline Kode & \multicolumn{1}{c}{ Task/Tugas } \\
\hline T1 & $\begin{array}{l}\text { Login ke dalam sistem sebagai } \\
\text { user }\end{array}$ \\
\hline T2 & $\begin{array}{l}\text { Melihat halaman home dan klik } \\
\text { salah satu wisata }\end{array}$ \\
\hline T3 & Melihat detail wisata \\
\hline T4 & Melihat maps atau lokasi wisata \\
\hline T5 & Melakukan pemesanan tiket \\
\hline T6 & $\begin{array}{l}\text { Melihat history pemesanan tiket di } \\
\text { halaman profile }\end{array}$ \\
\hline
\end{tabular}

\section{a. Efisiensi}

Tingkat efisiensi pada tahap penelitian ini dihitung dengan dua cara yaitu menggunakan time based efficiency dan overall relatif efficiency. Perhitungan waktu dilakukan ketika reponden mengerjakan task sampai menyelesaikan task. Berdasarkan rumus (3) time based efficiency dapat diperoleh waktu seperti pada tabel 2 di bawah ini :

Tabel 2 Time Based Efficiency

\begin{tabular}{cc|l}
\hline Task & Efisiensi Waktu & \\
\hline T1 & 0,122215 & \\
\hline T2 & 0,131984 & \\
\hline T3 & 0,223399 & \\
\hline T4 & 0,127239 & \\
\hline T5 & 0,064799 & \\
\hline T6 & 0,064799 & \\
\hline
\end{tabular}

Hasil nilai rata-rata efisiensi relatif keseluruhan dari Tabel 3 yaitu sebesar $94,91 \%$.

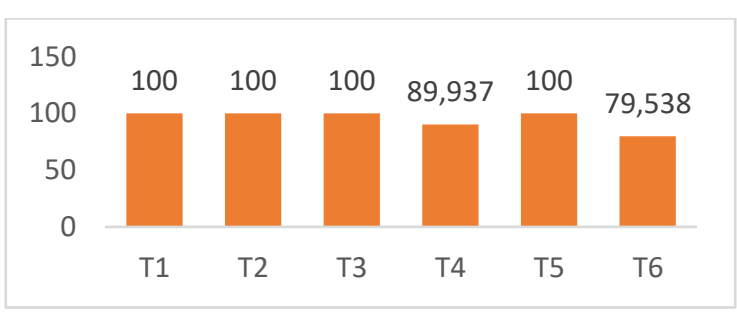

Gambar 10 Tingkat Efisiensi Relatif

Keseluruhan

Tingkat efektivitas diperoleh dari presentase keberhasilan pengguna dalam menyelesaikan task. Apabila responden berhasil menyelesaikan task maka responden akan mendapatkan nilai 1, sedangkan apabila responden gagal menyelesaikan task akan mendapatkan nilai 0 . Tabel 4 dibawah ini dihitung menggunakan Rumus (2)

Tabel 3 Tingkat Evektivitas

\begin{tabular}{cccc}
\hline $\begin{array}{c}\text { Kod } \\
\mathrm{e}\end{array}$ & $\begin{array}{c}\text { Jumlah } \\
\text { Task } \\
\text { yang } \\
\text { Berhasil } \\
\text { diKerjaka } \\
\text { n }\end{array}$ & $\begin{array}{c}\text { Jumlah } \\
\text { Responde } \\
\text { n }\end{array}$ & $\begin{array}{c}\text { Presentase } \\
\text { Keberhasila } \\
\text { n }\end{array}$ \\
\hline T1 & 30 & 30 & $100 \%$ \\
\hline T2 & 30 & 30 & $100 \%$ \\
\hline T3 & 30 & 30 & $100 \%$ \\
\hline T4 & 27 & 30 & $90 \%$ \\
\hline T5 & 30 & 30 & $100 \%$ \\
\hline T6 & 26 & 30 & $86,6 \%$ \\
\hline \multicolumn{5}{c}{ Rata-rata } & & \\
\hline & & & $96,1 \%$ \\
\hline
\end{tabular}

10. Hasil Uji Data Kuesioner SUS

Uji normalitas dilakukan dengan teknik Shapiro Wilk karena data yang digunakan memliki sample dibawah 50 orang. Untuk menggunakan uji shapiro wilk sampel data yang digunakan kurang dari 50 sampel $(\mathrm{N}<50)$. Dalam pengujian, suatu data dikatakan berdistribusi normal apabila nilai signifikansi $>0,05$ (sig. > 0,05). Dapat dilihat pada table 4.6 di bawah ini : 
Tabel 4 Uji Normalitas Shapiro Wilk

Kolmogorov-
Smorniov $^{\mathrm{a}}$

Statistic df Sig. Statistic df Sig.

$\begin{array}{lllllll}\text { Hasil } & .127 & 30 & .200^{*} & .969 & 30 & .517\end{array}$

Hasil uji normalitas pada table 5 Dapat dilihat dari nilai sig (signifikansi) dari uji Shapiro Wilk yaitu sebesar 0,517>0,05 signifikasi ( $\mathrm{p}>0,05)$, sehingga berdasarkan uji normalitas Shapiro Wilk data tersebut dapat dikatakan berdistribusi normal. Data yang sudah berdistribusi normal selanjutnya dapat dilakukan pengujian one sample t test. Dasar keputusan uji one sample t test dapat dilakukan dengan 3 cara yaitu membandingkan nilai $\mathrm{Sig}$ (Signifikan) dengan 0,05, membandingkan nilai $t_{\text {hitung }}$ dengan $t_{\text {tabel, }}$, serta melihat perbandingan nilai $t_{\text {hitung }}$ dengan $t_{\text {tabel }}$ melalui kurva.

Tabel 5 Hasil Uji One Sample T Test

\begin{tabular}{ccccc}
\hline & $\mathrm{N}$ & Mean & $\begin{array}{c}\text { Std. } \\
\text { Deviation }\end{array}$ & $\begin{array}{c}\text { Std.Error } \\
\text { Mean }\end{array}$ \\
\hline Hasil & 30 & 77.1667 & 13.09339 & 2.39051 \\
\hline
\end{tabular}

\begin{tabular}{|c|c|c|c|c|c|c|}
\hline \multirow{3}{*}{} & \multicolumn{9}{|c|}{ Test Value $=68$} \\
\cline { 5 - 7 } & $\mathrm{t}$ & df & $\begin{array}{c}\text { Sig. (2- } \\
\text { tailed) }\end{array}$ & $\begin{array}{c}\text { Mean } \\
\text { Difference }\end{array}$ & \multicolumn{2}{c|}{$\begin{array}{c}95 \% \text { Confidence Interval of } \\
\text { the Difference }\end{array}$} \\
\cline { 5 - 7 } & & & & & Lower & Upper \\
\hline Has & 3.8 & 29 & .001 & 9.16667 & 4.2775 & 14.0558 \\
il & 35 & & & & & \\
\hline
\end{tabular}

Berdasarkan output pada tabel 6 Diatas terdapat One-sample statistic yang merupakan statistic deskriptif dari data penelitian yang dianalisis, dimana $\mathrm{N}$ atau jumlah data yang diinput adalah 30 orang/sampel. Kemudian mean (nilai rata-rata) sebesar 77,1667, Std.Devination 13.09339, dan Std.Error Mean sebesar 2.39051. Selanjutnya output dari OneSample Test, penulis akan mengambil keputusan berdasarkan nilai Sig. Hasil OneSample Test pada tabel 6 Menunjukkan nilai Sig. (2-tailed) adalah sebesar 0,001, karena nilai Sig. (2-tailed) lebih kecil dari 0,05 maka sesuai dengan dasar pengambilan keputusan $\mathrm{H}_{0}$ ditolak dan $\mathrm{H}_{1}$ diterima. Jadi nilai rata-rata skor SUS pada prototype aplikasi tiket wisata di Pemalang tidak sama dengan $68 . \mathrm{H}_{1}$ diterima dengan nilai rata-rata skor SUS pada prototype aplikasi tiket wisata di Pemalang tidak sama dengan 68 sesuai dengan hasil rata-rata SUS 77,1667 atau bisa dikatakan Baik (B).

\section{KESIMPULAN}

Kesimpulan dari penelitian ini adalah dengan adanya hasil perancangan prototype Aplikasi Tiket Wisata di Kota Pemalang, maka pengukuran usability pada prototype aplikasi tiket wisata Pemalang memenuhi tingkat efisiensi dengan nilai relatif keseluruhan sebesar 77,1667, tingkat efektivitas presentase dari keseluruhan task seluruh reponden sebesar $96,1 \%$.

Pengukuran tingkat kepuasan pengguna terhadap prototype Aplikasi Tiket Wisata di Kota Pemalang menggunakan metode System Usability Scale (SUS), mendapat hasil skor rata-rata yang didapat yaitu 77,1667 dimana hasil ini memiliki nilai rata-rata usability lebih dari 68. Hasil uji data menggunakan uji normalitas shapiro wilk, dapat disimpulkan $\mathrm{H}_{1}$ diterima dengan nilai rata-rata skor SUS tidak sama dengan 68. 


\section{DAFTAR PUSTAKA}

[1] P. Tiket, W. Di, and K. Kuningan, "Pemesanan tiket wisata di kabupaten kuningan berbasis mobile," 2020.

[2] B. Saputra, R. N. Amanda, and N. Patriani, "Analisis Sistem Informasi Pemesanan Tiket Pada Travel Okka Wisata Pontianak," Sensitek 2018, no. April, pp. 590-594, 2018.

[3] O. Septian, "Analisa perancangan sistem informasi pemesanan tiket museum online di dki jakarta berbasis web," vol. 10, no. 1, pp. 1-5, 2019.

[4] P. P. Rex Hartson, The UX Book: Process and Guidelines for Ensuring a Quality User Experience. 2012.

[5] A. C. Wardhana, N. Anggraini, N. F. Rozy, and L. Belakang, "Aplikasi Backpacker Itinerary Dengan Menerapkan Metode User Experience ( UX ) Lifecycle of Informatics Engineering Program Faculty of Science and Technology Islamic State University Syarif Hidayatullah Jakarta 1 Student 23 Lecturer of Informatics Engineer," 2010.

[6] K. R. Hadi, H. M. Az-zahra, and L. Fanani, "Analisis Dan Perbaikan Usability Aplikasi Mobile KAI Access Dengan Metode Usability Testing Dan Use Questionnaire," J. Pengemb. Teknol. Inf. dan Ilmu Komput., vol. 2, no. 9, p. 2743, 2018, [Online]. Available: http://j-ptiik.ub.ac.id.

[7] I. A. H.N, P. I. Nugroho, and R. Ferdiana, "Pengujian Usability Website Menggunakan System Usability Scale," J. IPTEKKOM J. Ilmu Pengetah. Teknol. Inf., vol. 17, no. 1, p. 31, 2015, doi: 10.33164/iptekkom.17.1.2015.31-38.

[8] R. A. Murdiono, H. Tolle, and A. P. Kharisma, "Evaluasi User Experience Pada Aplikasi Mobile Penjualan Tiket Online," $J$. Pengemb. Teknol. Inf. dan Ilmu Komput., vol. 2, no. 5, pp. 2078-2085, 2018.

[9] U. Ependi, A. Putra, and F. Panjaitan, "Evaluasi tingkat kebergunaan aplikasi Administrasi Penduduk menggunakan teknik System Usability Scale," Regist. J. Ilm. Teknol. Sist. Inf., vol. 5, no. 1, p. 63, 2019, doi: 10.26594/register.v5i1.1412.

[10] B. Pudjoatmodjo and R. Wijaya, "Tes Kegunaan (Usability Testing) Pada Aplikasi Kepegawaian Dengan Menggunakan System Usability Scale," Semin. Nas.
Teknol. Inf. dan Multimed. 2016, pp. 37-42, 2016.

[11] R. Rizawanti, I. K. Resika Arthana, and P. W. Arta Suyasa, "Usability Testing Pada Aplikasi Hooki Arisan Dengan Model Pacmad Menggunakan Pendekatan Gqm," Kumpul. Artik. Mhs. Pendidik. Tek. Inform., vol. 8, no. 1, p. 33, 2019.

[12] J. R. Lewis and J. Sauro, "The factor structure of the system usability scale," Lect. Notes Comput. Sci. (including Subser. Lect. Notes Artif. Intell. Lect. Notes Bioinformatics), vol. 5619 LNCS, pp. 94103, 2009, doi: 10.1007/978-3-642-028069_12.

[13] A. W. Soejono, A. Setyanto, and A. F. Sofyan, "Evaluasi Usability Website UNRIYO Menggunakan System Usability Scale (Studi Kasus: Website UNRIYO)," J. Teknol. Inf., vol. XIII, no. 1, pp. 29-37, 2018, [Online]. Available: http://jti.respati.ac.id/index.php/jurnaljti/arti cle/view/213.

[14] U. Ependi, T. B. Kurniawan, and F. Panjaitan, "System Usability Scale Vs Heuristic Evaluation: a Review," Simetris J. Tek. Mesin, Elektro dan Ilmu Komput., vol. 10, no. 1, pp. 65-74, 2019, doi: 10.24176/simet.v10i1.2725.

[15] A. Nioga, K. C. Brata, and L. Fanani, "Evaluasi Usability Aplikasi Mobile KAI Access Menggunakan Metode System Usability Scale ( SUS ) Dan Discovery Prototyping ( Studi Kasus PT KAI )," J. Pengemb. Teknol. Inf. dan Ilmu Komput. Univ. Brawijaya, vol. 3, no. 2, pp. 89528958, 2019. 